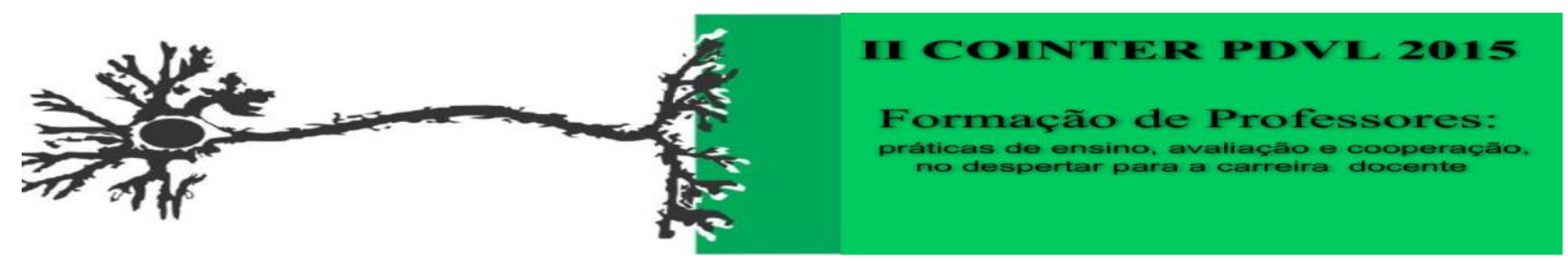

\title{
APRENDIZAGEM SIGNIFICATIVA E GEOMETRIA: DESENVOLVIMENTO E CRESCIMENTO MATEMÁTICO
}

\author{
Apresentação: Comunicação Oral \\ Manassés da Silva Batista ${ }^{1}$; Raimundo Nonato Ferreira Tito Filho ${ }^{2}$; Antonio Kennedy Lopes \\ Dantas $^{3}$; Francismar Holanda ${ }^{4}$
}

\section{Resumo:}

Neste trabalho propomos uma prática educacional voltada para Unidades de Ensino Potencialmente Significativas definidas por Moreira (2011) que são auxiliadas por atividades envolvendo geometria. Apresentamos resultados de uma pesquisa em que investigamos a ocorrência de aprendizagem significativa de 40 estudantes envolvidos na atividade do $3^{\circ}$ ano do ensino médio, do colégio Estadual Zacarias de Góis -liceu de Teresina, Piauí. Diante da dificuldade apresentada pelos estudantes em compreender assuntos de geometria plana e espacial como: teorema de Thales, semelhança de triângulos e uma maior compreensão de geometria espacial. Com isso a intervenção pedagógica se tornou necessária e para tanto propomos uma atividade de forma lúdica para propiciar, de maneira atrativa, uma melhor forma de se obter o conhecimento sobre projeções e objetos, visando ainda buscar uma aprendizagem associada ao estudo da geometria em 3D . O trabalho foi desenvolvido no âmbito do Programa de iniciação à docência (Pibid) e na Perspectiva da Educação Matemática no ensino médio. As observações que fizemos mostra alguns elementos que indicam que as práticas contemplam princípios conceituais e metodológicos que norteiam uma UEPS. A partir da identificação desses elementos analisamos os educandos no decorrer do desenvolvimento da UEPS mediada por exercícios de geometria, podemos avaliar que os princípios básicos para a ocorrência de aprendizagem significativa bem como a sinalização de reconciliação integradora e de diferenciação progressiva puderam ser evidenciados. Neste

\footnotetext{
${ }^{1}$ Licenciatura em matemática, Instituto Federal do Piauí (IFPI), E-mail: Manassess923@gmail.com

${ }^{2}$ Licenciatura em matemática, Universidade Estadual do Piauí (UESPI), E-mail: prof.titofilho@ hotmail.com

${ }^{3}$ Licenciatura em matemática, Instituto Federal do Piauí (IFPI), E-mail: kennedylopesdantas@ @otmail.com

${ }^{4}$ Mestre em Matemática, Instituto Federal do Piauí, E-mail: Frholanda@ifpi.edu.br
} 
sentido, a inclusão de trabalhos em sala de aula na UEPS pode estimular no que se refere à sua capacidade de promover a aprendizagem significativa dos estudantes.

Palavras-chave: Aprendizagem significativa; UEPS; Geometria em 3D; Teorema de Tales

\section{Introdução}

A teoria da Aprendizagem Significativa corresponde a uma proposta psicoeducativa em uma perspectiva cognitivista formulada por David Ausubel na década de 1960. Ausubel compreende a Aprendizagem Significativa como uma série de mudanças do conhecimento e para tanto, reconhece a importância dos processos cognitivos dos estudantes, que ocorrem em uma interação entre as informações recentes e a estrutura cognitiva. David Ausubel ao longo da elaboração de sua teoria, especialmente entre as décadas de 1960 e 1980, identificou condições necessárias para a ocorrência de aprendizagem significativa: a aplicação de ferramentas potencialmente significativa nas práticas de ensino; a presença, na estrutura cognitiva do estudante, de conhecimentos prévios oportunizam o relacionamento do que o educando já sabe com os conhecimentos recém-adquiridos. Ao trabalharmos na escola referenciada a cima, percebemos uma grande dificuldade dos estudantes em entender os conceitos e aplicações de geometria plana na disciplina de Matemática. Os mesmos não conseguiam alcançar os objetivos propostos em aulas, como localizações de ângulos, identificação de figuras espaciais, desenvolvimento de teoremas importantes como teorema de tales. Percebemos, então, que uma das alternativas seria trabalhar com a aprendizagem significa por intermédio das UEPS para facilitar o aprendizado. Assim, preparamos aulas teóricas e práticas referentes a geometria 3D para que eles pudessem vivenciar aplicações práticas do que estavam estudando na teoria. Esperando que os ensinos nessas aulas possibilitassem um entendimento claro do significado real dos conteúdos, e ter uma oportunidade de refletir sobre a iniciação da prática docente. Nesse contexto abordamos vários assuntos dentre eles a projeções 3D que se dá por meio de feixes que podemos fazer relações com o teorema de tales. $\mathrm{Na}$ análise das atividades evidenciamos elementos que sinalizam que a UEPS planejada e estruturada com a inclusão de atividades de modelagem matemática atende aos princípios educacionais e metodológicos caracterizados por Moreira (2011). A partir da identificação desses elementos, a análise de todo o processo nos leva a conjecturar que o estudo da geometria na UEPS pode fortalecê-la no que se refere à sua capacidade de promover a aprendizagem significativa dos estudantes.

\section{Fundamentação Teórica}


A UEPS é construção de uma seqüência de ensino baseado em teorias propostas na aprendizagem, em especial da aprendizagem significativa. Partindo do pressuposto de que não há nenhum ensino sem aprendizagem, que o ensino é o meio e o aprendizado é o objetivo, propõe-se que sequiência como uma Unidade de Ensino potencialmente significativas (UEPS). Sequências de ensino que se baseiam em tese, orientada a aprendizagem significativa, não mecânico. Assim para configurar a UEPS tem haver aspectos, como:

1. Definir o tema específico que será abordado, identificando aspectos importantes no processo em que permitam o uso do material de ensino que é inserido a parti do tema escolhido;

2. criar e propor situações como: discussão, questionário, situação-problema. Para que o estudante possa exteriorizar o seu conhecimento prévio, aceito ou não aceito no contexto do material de ensino supostamente relevantes para a aprendizagem significativa da matéria (objetiva) em questão;

3. Propor situações problemáticas em um nível muito introdutória, tendo em conta o conhecimento prévio do aluno, para preparar o terreno para a introdução do conhecimento para ser ensinado; estas situações problemáticas podem incluir, podem servir como organizador de antecedência; são situações que dão sentido a novos conhecimentos, mas que os estudantes devem perceber como problemas e deve ser capaz de modelá-los mentalmente; modelos mentais são funcionais para o educando e resultam na percepção do conhecimento prévio; estas situações-problema inicial pode propor, através de simulações, demonstrações, vídeos, problemas diárias, problemas clássicos de materiais didáticos, dentre outros. Mas sempre forma acessível e problemático, como uma forma para despertar o interesse.

4. Uma vez trabalhou as situações iniciais, o conhecimento é para ser apresentado ensinado e aprendido, considerando a diferenciação progressiva, isto é, começando com

Em termos mais gerais, inclusive, dar uma primeira visão de tudo, o que é aspectos mais importantes na unidade de ensino, mas exemplos posteriores são dadas, abordando aspectos específicos; o ensinando estratégia pode, por exemplo, uma exposição de curta duração seguido por atividade oral juntos em pequenos grupos, por sua vez, tem de ser seguido por uma apresentação ou atividade discussão no grande grupo;

5. então os estruturais (ou seja, aspectos mais gerais são tomadas, que é ensinar de forma eficaz), o conteúdo da unidade de ensino, nova apresentação (Que pode ser por meio de outro breve apresentação oral de um recurso concreto, um texto, etc), mas com uma complexidade mais elevada em relação ao primeiro nível de desempenho; o situações-problema deve ser proposta em níveis crescentes de complexidade; dar novos exemplos e destacar semelhanças e 
diferenças em relação às situações e exemplos já trabalhados, ou seja, promover a reconciliação inclusive; após esta segunda apresentação deve ser propor alguma outra atividade colaborativa que leva os alunos a interagir socialmente, negociação de significados, com o professor como mediador; esta atividade pode ser a resolução de problemas, a construção de um material concreto, um experimento laboratório, um projeto pequeno, etc., mas deve ser necessariamente negociar significados e mediação docente;

6. concluindo a unidade, é dada continuidade ao processo de retomar a diferenciação progressiva mais conteúdo relevante em questão, procurando a reconciliação integradora; isso deve ser feito através de um novo apresentação dos significados que pode ser, mais uma vez, um breve apresentação oral, a leitura de um texto, recurso computacional, concreto e audiovisual, etc.; o que importa não é a estratégia em si, mas a forma para trabalhar o conteúdo da unidade; após esta terceira apresentação, deve ser proposta e trabalhar novas situações problemáticas em um nível mais elevado de complexidade em relação à situações anteriores; tais situações devem ser resolvidas em atividades colaborativas e depois apresentados e discutidos no grupo grande, sempre com a mediação do professor;

7. Avaliação da aprendizagem na UEPS deve ser realizada ao longo de sua implementação, escrever tudo o que pode ser considerado uma prova de conteúdo de aprendizagem significativa a mesma; Além disso, deve haver uma avaliação somativo após o sexto passo, que devem propor questões de situações que envolvem a compreensão, que expressam um captador de significados e, idealmente, qualquer capacidade de transferência; tais problemas de situações devem primeiro ser validado por professores experientes no domínio da educação; avaliação desempenho dos estudantes em UEPS deve basear-se, em pé de igualdade, tanto nas tarefas situações resolvidas de forma colaborativa, registros de professores e avaliação formativa como na avaliação sumativa;

8. única UEPS ser considerado bem sucedido se a avaliação do desempenho dos alunos fornece evidências de aprendizagem significativa como,coleção de significados, compreensão, capacidade de explicar, de aplicar o conhecimento para resolver situações-problema. A aprendizagem significativa é progressiva, o domínio de um campo conceitual é progressiva; por isso, a ênfase em evidências, durante todo o processo.

\section{Geometria 3D}

A percepção de espaço é sem dúvida uma das primeiras sensibilidades que o ser vivo pode sentir. Dessa forma, o ensino da Geometria com toda a sua série de propriedades 
métricas, de elementos formais e da Matemática como um todo e seu raciocínio lógico são fatores determinantes para o aprimoramento dessa noção.

$\mathrm{O}$ efeito $3 \mathrm{D}$ que estaremos considerando aqui, são desenhos feitos em planos que dependendo do ângulo de visão nos passa a ideia de objeto real, ou mesmo peças trabalhadas que vistas de ângulos diferentes nos dão um efeito ilusório, sem que seja necessário a utilização de óculos próprios para que se consiga ter tal efeito. São Desenhos que ganham um efeito que parecem saltar do papel, e estes já são considerados uma arte em diversos lugares. As exposições de desenhos, pinturas, esculturas, e objetos feitos em madeira, de diversos artistas ganham o mundo. Essas artes começam a ganhar uma importância relevante na educação da matemática.

Assim tratando à possibilidade da geometria ser um conteúdo importante e necessário para desenvolver nos educandos a aprendizagem de resolução de problemas de sua vida fora da escola, visando alcançar objetivos educacionais complementares. Neste sentido, em algumas situações abordadas por meio desse trabalho, os estudantes se depararam diante de um obstáculo para o qual não possuem, provisoriamente, conhecimentos suficientes para superá-lo, emergindo assim a necessidade de construir essas Investigações em Ensino de matemática. Logo, os estudantes aprimoraram conceitos já construídos quanto constroem outros diante da necessidade de seu uso.

\section{Geometria e o Teorema de Tales}

A proporcionalidade, principalmente na forma do teorema de Tales ou de semelhança de triângulos, foi um dos conhecimentos geométricos mais uteis ao longo dos tempos. Foi com a semelhança de triângulos que Aristarco comparou as distâncias da terra e à lua e da terra ao sol, que Eratóstenes calculou o raio da terra, e que os matemáticos árabes estabeleceram as razões trigonométricas. Tales de Mileto (624 a.C -547 a.C), considerado um dos mais versáteis gênios da antiguidade, levou para a Grécia a geometria dos egípcios e começou a aplicar a ela os procedimentos da filosofia grega. Com seu método de comparar sombras, hoje conhecido como teorema de Tales, realizou muitos cálculos inéditos até então, como obter a altura de uma pirâmide. O teorema de tales é enunciado da seguinte forma: Se duas transversais intersectam um feixe de retas paralelas, então a razão entre dois segmentos quaisquer de uma transversal é igual à razão dos segmentos correspondentes da outra. Podemos comprovar esse teorema numa perspectiva de geometria $3 \mathrm{D}$, dado por uma projeção: 


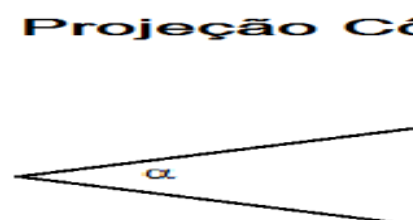

Estabelecendo razões temos que $: \frac{O A 1}{A 1 A^{\prime}}=\frac{O A 2}{A 2 A^{\prime 2}}=\frac{O A 3}{A 3 A^{\prime} 3}$, podemos enunciar o teorema de Tales como segue: um feixe de paralelas determina, em duas transversais quaisquer, segmentos proporcionais. Em decorrência das propriedades das proporções, valem as igualdades: $\frac{O A^{\prime}}{O A 1}$ $=\frac{O A \prime 2}{O A 2}=\frac{O A^{\prime} 3}{O A 3}$.

\section{Metodologia}

O desenvolvimento da UEPS para a implementação dos assuntos de geometria 3D e teorema de Thales teve duração de 20 horas aula, distribuídas em 10 encontros de aulas regulares além de um encontro no final da atividade que viabilizou uma oficina da geometria em 3D. Assim nos encontros 1 e 2: avaliação dos conhecimentos prévios através de uma lista de exercícios, Exposição do projeto e alguns vídeos a respeito do tema. Nos encontros 3 e 4: A história da geometria 3D e suas contribuições Assuntos que envolve a geometria em 3D dentre eles o teorema de Tales e sua história. Isso permitiu outras atividades nos encontros 5, 6 fundamentação e avanço na complexidade dos assuntos com simulações da geometria 3D no cotidiano através de aulas colaborativa e participativas. Nos encontros 7, 8, 9 foi realizado uma oficina em 3D onde os educandos tiveram a oportunidade de desenvolver e compreender na prática com materiais concretos. No encontro 10 houve uma avaliação das atividades por parte dos estudantes através de uma lista.

Como base no conteúdo: definições básicas e mais gerais são necessárias para viabilizar a compreensão da geometria em 3D, contudo, a explicação da situação inicial exigiu conceitos específicos sobre geometria plana, outras atividades foram propostas a fim de promover o entendimento dos procedimentos matemáticos, com potencial de serem aplicáveis a diferentes situações do cotidiano. Avanço em complexidade, do conteúdo matemático: nova situação problema foi proposta como as projeções que norteiam a geometria 3D de modo a exigir maior envolvimento dos estudantes no processo da prática, bem como a avançar em 
complexidade do assunto. A partir da nova problemática apresentada, considerada do segundo momento, deu-se a conceitualização de geometria em 3D de modo geral.

Os casos envolvendo teorema de Tales foi convenientemente abordado através de apresentação de slides e exercícios relacionados com o cotidiano dos estudantes como descobrir medidas de distância através da semelhança de triângulos. Finalização com atividades colaborativas: Em 5 grupos de 8 estudantes um ambiente de trabalho colaborativo, os educandos participaram da oficina em 3D onde possibilitou uma revisão de conceitos iniciais e outros mais avançados estudados durante a unidade de ensino; desse modo, discussão, simulação e visualização de resultados permitiram um maior significado e esclarecimento de conceitos matemáticos.

\section{Primeiro momento- exercícios com o teorema de Tales}

Inicialmente foi dada uma lista de 8 questões para avaliar os conhecimentos prévios dos 40 estudante a respeito do tema que iria ser abordado no projeto e logo após os estudantes assistiram 2 vídeos sobre geometria 3D e projeções e logo após foi dado a história e o assunto sobre o teorema de Tales e através de slides e exposição de materiais concretos, atividades em grupos de forma colaborativa que envolvia a geometria 3D e sua importância dentro do projeto a ser desenvolvido, tudo isso em 6 encontros.

\section{.Segundo Momento - Oficina em 3D}

Para que fosse realizada a oficina foram divididos 8 grupos com 5 educandos cada. Com os seguintes materiais: 8 lanternas a lazer, 8 cartolinas de diversas cores, 8 mesas, 8 cabos de vassouras com base para a fixação, 8 lápis de cor, 8 réguas de $30 \mathrm{~cm}$, celulares dos próprios estudantes, sólidos de 15 a $20 \mathrm{~cm}$ para serem projetados na cartolina. Feita projeção de um sólido, como por exemplo, um prisma ou uma pirâmide. Esses objetos são mais fáceis de planificar, e isso faz com que os educandos possam assimilar a ideia central da projeção. Cada grupo deve escolher um colega, ou seja, um (estudante A) para ser o observador (olho). Esse observador vai manipular a lanterna que estará no topo do cabo de vassoura, que estará posicionada entre $1,5 \mathrm{~m}$ e $2 \mathrm{~m}$ de distância da mesa do grupo. Esse (estudante A) deve focar raio do lazer em cada um dos vértices do objeto que esteja Sobre sua visão, de maneira que este raio, ao se retirar o objeto, também intercepte a Folha de cartolina, outro (estudante B) de posse de um lápis deverá marcar a projeção do vértice na folha de cartolina. Fazendo isso para cada vértice, (estudante C) deverá retirar o objeto e então o (estudante B) marcará o ponto onde a luz do lazer atingiu a cartolina. 
Figura 2- Cenário da Oficina

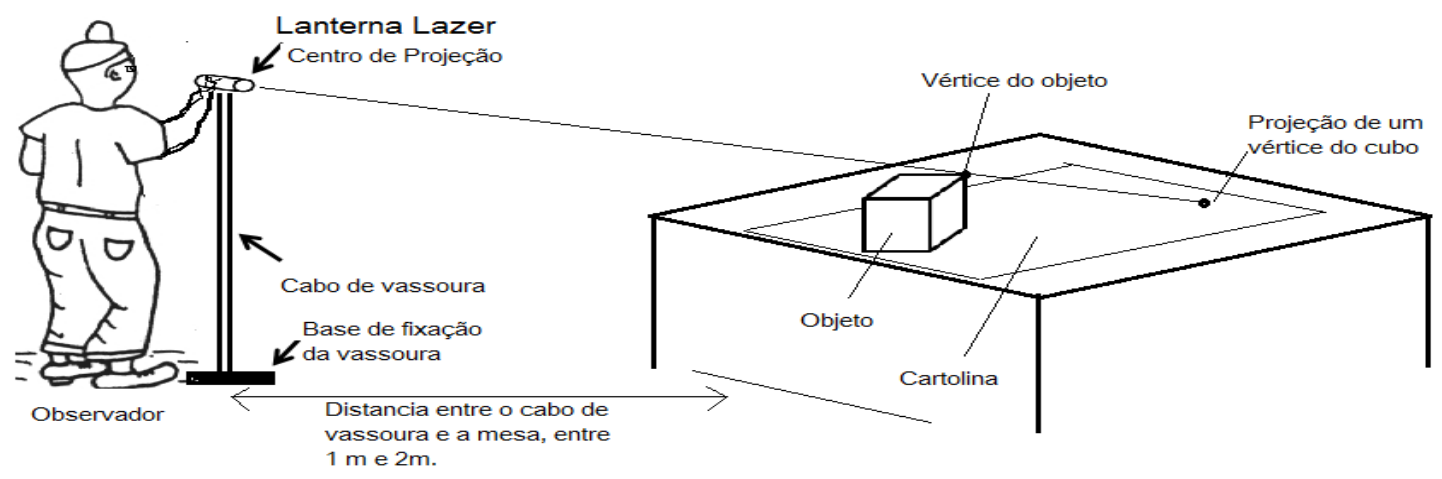

\section{Na prática}

Os estudantes perceberam que para se fazer as projeções desejadas, bastava utilizar os fundamentos estudados em sala de aula como o teorema de Tales aplicado a projeções e que precisariam uma distância adequada ao tamanho da cartolina para fazer as projeções. Foi trabalhado o posicionamento do instrumento e as ultimas instruções, como prestar atenção aonde o laser iria tocar a cartolina e assim fazer as marcações adequadas e logo após tirar a foto com o celular do ponto em o laser estava. Como veremos a seguir:

Figura 3- a projeção do cubo com o laser

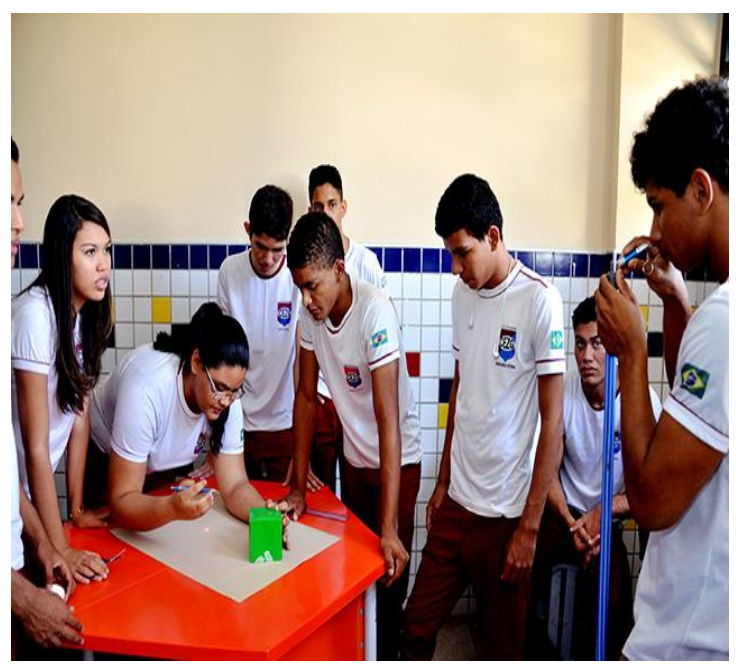

Figura 4- Cubo projetado no plano

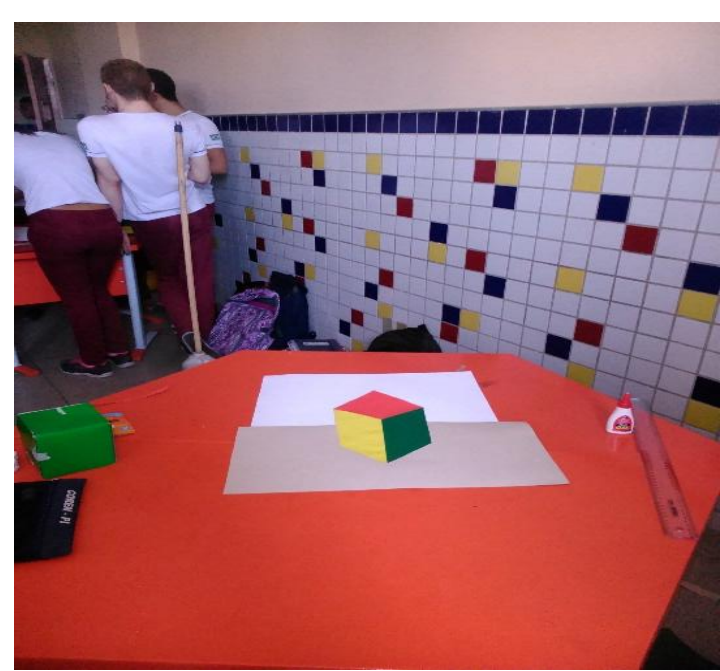





\section{Resultados e Discussão}

Com o objetivo de aprimorar nossos trabalhos na docencia, foi entregue um questionario contendo cinco questões para cada educando. Apresentamos a seguir o comentário de alguns que aqui denominamos com as seguintes siglas (T1, T2, T3, G1 e G2) que demonstraram uma peculiar reflexão sobre a atividade e que nos motivaram a sempre analisarmos e buscarmos novos métodos de ensino da matemática em nossa prática docente.

Figura 7 - comentário do T1

Figura 8 - comentário do T2

2) Qual a sua opinião sobre essa atividade? Deveria ser feita atividades iguais a esta mais vezes? Por

Oprojeto foi bern lúdico, os alunos puderom apender com os puofessores métodos diaurtidos de apuender a geometria 3D. Sim. Porque desuria se sair de uma uisa repetitisur e aprender algo de uma forma disuertida. 
9

Figura 9 - comentário do T3

3) Essas atividades contribuiu para a aprendizagem do assunto de geometria ensinado na sala de aula? Por que? Sim.

Porque com a prética a ginte caparenole mair rajido do oque usó com teociar.

Figura 10- comentário do G1

4) Como você qualifica essas atividades? Justifique.

X Excelente

( ) Legal

( ) Divertida

( ) Essencial
( ) Ruim

( ) Péssima

( ) Desorganizada

( ) Nada a declarar

Pois havia bons materiais, for organizado i a equipe é ben qualificada.

Figura 11 - Comentário do G2

5) Através dessas atividades você se sentiu capaz e motivado para aprender outros conteúdos de matemática? Por que?

Sim, parque con essa atividade en aprende a entergar a matemática de autro modo, e que ela pode ser interessante e produtiva. 
Como foi possível observarmos, os estudantes expressam com nítida clareza que Através da Aprendizagem significativa e UEPS proporcionou a vivencia na prática o uso da matemática e o que lhes foi apresentado na teoria puderam atribuíram maior significado aos conceitos apresentados em sala de aula, contribuindo assim para um desempenho mais amplo em assuntos matemáticos. Proporcionaram aos educandos maior interação e reforçaram que o lúdico e a organização das fases da UEPS no ambiente escolar pode ajudar no desenvolvimento dos educandos. Assim, através das repostas ao questionário entregue para os educandos no final da atividade, chegamos a essas afirmações que podem ser comprovadas de acordo com a figura abaixo:

Figura 12- Resultados da avaliação direta

\section{Conclusões}

A relevância desse projeto foi discutida no momento, com os envolvidos no trabalho e analisando a situação, percebemos o valor dessa vivência para que os mesmos compreendam que a prática exige muito mais cuidados e que muitas das vezes estes não são bem especificados nos livros. Notamos a necessidade de oferecer à turma mais que aulas padronizadas no paradigma tradicional e que há diversas maneiras de dá mais significado à Matemática, fazendo aulas criativas e desafiadoras. Expondo o interesse em aprender e sentirem-se capazes de relacionar a aprendizagem escolar para além dos muros da escola de maneira prazerosa tanto para o docente como para o discente. Considerando os resultados mostrados aqui, que caracteriza a construção de Unidades de Ensino Potencialmente Significativas, mostramos situações que permitem inferir que conteúdos matemáticos podem ser integrados em UEPS de forma a proporcionar condições favoráveis à aprendizagem significativa dos educandos.

O planejamento e a execução de uma unidade de ensino para o estudo da geometria em 3D exemplificam um caso em que há indícios de que esta integração favorece a 
aprendizagem. Neste sentido, entendemos que a execução de UEPS e a geometria, possibilita potencializar a ocorrência de aprendizagem significativa. Os estudantes com o passar do tempo já estavam mais familiarizados com o encaminhamento dos exercícios e com isso houve uma maior participação que pode ser observada. Com esta atividade foi possível buscar uma reconciliação integradora no sentido de que conceitos já estruturados em atividades anteriores precisariam ser adequadamente articulados na oficina 3D. Por fim, quanto a UEPS apresentada neste trabalho, podemos considerá-la prazerosa, dadas as evidências de aprendizagem significativa dos envolvidos na pesquisa.

\section{Referências}

AUSUBEL, D. P., NOVAK, J. D.; HANESIAN, H. (1980). Psicologia Educacional. Trad. Eva Nick. $2^{a}$ edição. Rio de Janeiro: Interamericana.

DANTE, LUIZ ROBERTO. Matemática: conceito e aplicações/ Luiz Roberto Dante, vol1. São Paulo: Ática, 2010.

HOLANDA, F. (2014). Oficina de geometria em 3D: uma ferramenta para estimular a aprendizagem da geometria nas etapas do ensino médio. Dissertação de Mestrado; UFPIPI.

MOREIRA, M. A. (1999). Aprendizagem Significativa. Fórum Permanente de professores. Brasília: Ed. Universidade de Brasília.

MOREIRA, M. A. (2011). Unidades de enseñanza potencialmente significativas - UEPS. Aprendizagem Significativa em Revista. V1(2), pp. 43-63. Acesso em 30 de setembro de 2015, http://goo.gl/OGGLz8

NETO, ANTONIO CAMINHA MUNIZ. Tópicos de matemática Elementar: geometria euclidiana plana. 2ed. - Rio de janeiro: SBM, 2013 - coleção Professor de matemática. 